\title{
Small Stem Total Hip Arthroplasty in Hypoplasia of the Femur
}

\author{
F. Harald R. De Man MD, Daniel Haverkamp MD, PhD, \\ Harm M. Van der Vis MD, PhD, Philip P. Besselaar MD, PhD, \\ René K. Marti MD, PhD
}

Received: 30 July 2007 / Accepted: 13 February 2008/Published online: 15 March 2008

(C) The Author(s) 2008

\begin{abstract}
Total hip arthroplasty in hypoplastic femurs is technically difficult and the incidence of complications and aseptic loosening is relatively high. Cemented, uncemented, off-the-shelf, and custom-made stems all have been advocated in these cases. From 1978 to 1997, we performed 86 total hip arthroplasties in 77 patients with a hypoplastic femur using a cemented, off-the-shelf, small, curved, cobaltchromium stem. We hypothesized results equaled those of the identical but larger-sized stems in normal-sized femora which were used as comparisons. Clinical and radiographic evaluations were performed. Minimum followup was 4.2 years (mean, 12 years; range, 4.2-20.3 years); mean Harris hip score was 88 , and mean hip flexion was $104^{\circ}$. Six stems were revised: four because of aseptic loosening, one after a femoral fracture, and one because of malpositioning. Complications included one perforation and one fracture of the femur, one fracture, one nonunion of the greater
\end{abstract}

Each author certifies that he or she has no commercial associations (eg, consultancies, stock ownership, equity interest, patent/licensing arrangements, etc) that might pose a conflict of interest in connection with the submitted article.

Each author certifies that his or her institution has approved the reporting of these cases, that all investigations were conducted in conformity with ethical principles of research, and that informed consent for participation in the study was obtained.

F. H. R. De Man, D. Haverkamp, P. P. Besselaar, R. K. Marti Department of Orthopaedic Surgery, Academic Medical Centre, University of Amsterdam, Amsterdam, The Netherlands

F. H. R. De Man $(\bowtie)$

Hengstdal 3, 6522 JV Nijmegen, The Netherlands

e-mail: harald.deman@gmail.com

H. M. Van der Vis

Department of Orthopaedic Surgery, Tergooiziekenhuizen

locatie Hilversum, Hilversum, The Netherlands trochanter, and one deep infection. Implant survivorship for all hips at 15 years with aseptic revision of the stem as the end point was $90 \%$ (confidence interval, 82-99) which equaled results of the larger stems. The small off-the-shelf cemented Weber stem has a high long-term survival and a low complication rate. Survival compares favorably with other small-sized total hip systems.

Level of Evidence: Level III, therapeutic study, casecontrol.

\section{Introduction}

Since 1974 at our institution we have been using a cemented cobalt-chromium rotation THA, occasionally in combination with an acetabular roof augmentation, using two or three small, triangular-shaped femoral head autologous grafts [12, 43]. In 2004, de Jong et al. reported a long-term followup study of a single-surgeon series of all primary THAs of all available stem sizes performed with this approach [13]. Results at 15 years were good with a cumulative survival with aseptic loosening as an end point of $81.5 \%$ for the stem and $89.2 \%$ for the socket [13].

In THA for primary osteoarthritis (OA), standard-sized total hip components and a regular surgical technique are sufficient to obtain good long-term results with a low rate of complications. In OA secondary to preexistent anatomic deformities of the hip, eg, developmental dysplasia of the hip (DDH), spondyloepiphyseal dysplasia, juvenile osteonecrosis $(\mathrm{ON})$, and posttraumatic OA, surgery is more difficult [8, 26], clinical results are inferior [11, 21, 23, 45], and the complication rate is greater $[11,21,24,26]$ than in a patient group without these deformities. This may be the result of more frequent bone grafting, hypoplasia of the proximal femur with posterior migration of the greater 
trochanter requiring a smaller than usual femoral component [18], muscle contractures requiring muscular releases, or dislocation of the hip with difficulty in properly positioning components. The impact of inferior results in these patients is substantial because they typically are younger than the typical patient in whom THA is performed.

The numerous intermediate $[1,14,21,24,47,52]$ and long-term [5, 23, 25, 35, 39, 41, 46, 48, 49] followup reports of THA in patients with DDH typically focus on the diminished acetabular coverage in relation to fixation of the cup, and survivorship analyses with aseptic loosening of the cup as an end point have been reported [14, 24, 35, 39, $48,52]$ to range between $86 \%$ and $97.5 \%$ in intermediateterm studies [14, 24, 48, 52] and between $88 \%$ and $94 \%$ in long-term studies [35, 39]. However, the additional problems of the presence of a hypoplastic femur with a small intramedullary canal and the use of a smaller than usual femoral component seldom are discussed [14, 21, 23, 39, $41,46,48]$. There are even fewer reports of survivorship analysis of small-sized stems used in patients with DDH $[14,35,39]$. In these reports survival at 15 years with aseptic loosening as an end point has ranged between $92.4 \%$ and $96 \%$. The number of reports specifically addressing implantation of a stem component in a hypoplastic femur also is limited [16, 34, 47, 58], and survival as reported in two studies only, was $100 \%$ [34] at 9 years and $79 \%$ at 15 years [47]. Several studies on small stems report relatively high rates of complications such as perioperative femoral fracture $(10 \%)$ [58], (partial) nerve paralysis $(5 \%)$ $[21,58]$, recurrent dislocation $(16 \%)$ [58], and fracture of the component (5\%) [21]. Clinical outcomes seem to deteriorate with decreasing patient height and diameter of the femur [9]. Only five patients in the report by De Jong et al. [13] had a hypoplastic femur and subsequently received the smallest-sized Weber stem. We could not ascertain whether that subgroup had different results compared with patients with average-sized femora. Thus, there is still debate regarding the ideal choice of stem for femoral hypoplasia, whether cemented or uncemented, off-theshelf, or customized [3, 4, 7, 26, 34, 47, 58], and some have the opinion that patients with femoral hypoplasia have less good results than patients without femoral hypoplasia [26].

We hypothesized long-term survival, revision rates, clinical scores, and complication rates of the small cemented stem we used in patients with femoral hypoplasia were similar to those with larger-sized stems used in patients with a normal-sized femur.

\section{Materials and Methods}

Since 1978 we have been collecting data for all hip arthroplasties performed in our institution. From this database we identified two groups of patients: a study group of 77 selected patients (86 hips) with femoral hypoplasia who received the smallest available sized stem and a comparison group of 198 patients (231 hips) with normal femoral anatomy who received the identical curved type, but larger-sized stems. For both groups survivorship analyses, revision rates of the stems and cups, clinical scores, and incidence of surgical-related complications were assessed. We compared results between groups and also compared results of the small-stem study group with results of published reports of other small-stem hip systems.

Preoperative diagnoses in the hypoplastic small-stem group included: (1) DDH in 71 hips (83\%); classified according to Crowe et al. [11] as Grade I in 52 hips, Grade II in 13 hips, Grade III in two hips (Fig. 1), and Grade IV in four hips and with a mean CCD angle of $139^{\circ}$ (range, $\left.125^{\circ}-170^{\circ}\right)$; (2) primary $\mathrm{OA}$ in five hips and posttraumatic OA in five hips (12\% total); (3) ON in four hips (5\%), and (4) rheumatoid arthritis in one hip (1\%). Thirty-five hips (41\%) had previous surgery, including 27 femoral osteotomies, three pelvic osteotomies, and five other hip-related procedures. In the normal anatomy group preoperative diagnoses included primary OA in 148 hips (25\%), DDH in 58 hips (25\%), posttraumatic OA in seven hips (3\%), ON in

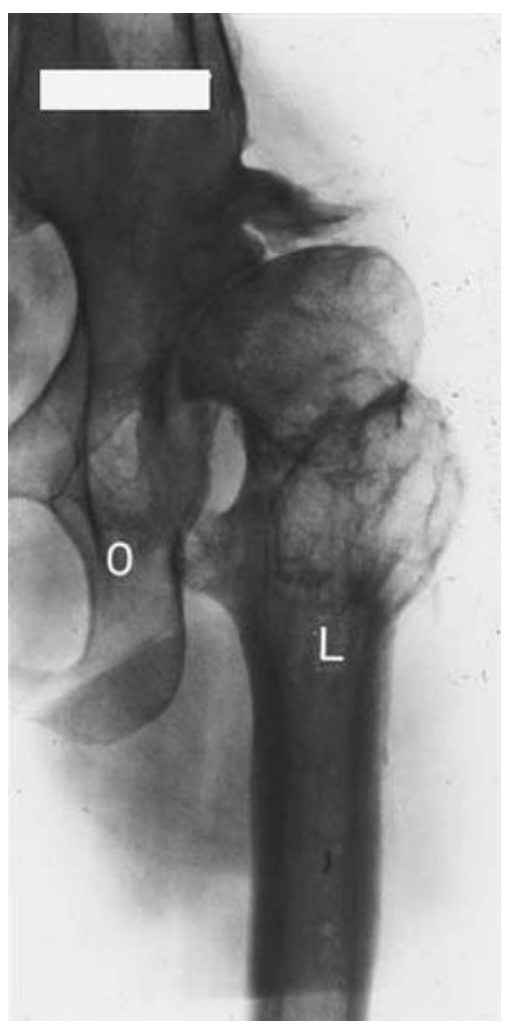

Fig. 1 This preoperative radiograph shows the left hip of a 49-yearold woman with bilateral femoral hypoplasia in the presence of developmental dysplasia of the hip and secondary OA. 
two hips (1\%), and rheumatoid arthritis in 58 hips (25\%). Previous surgery was performed in 53 hips $(23 \%)$ (Table 1). Twenty-one patients (21 hips) died after an average of 8.5 years postoperatively (range, 2.523.2 years), and one of these patients had a revision of both components after 7.8 years. Ten patients (12 hips or 14\%) were lost by last followup in the hypoplastic group and 43 patients (52 hips or 22\%) in the normal anatomy group; these patients were included in the survival analyses. Minimum followup in the hypoplastic group was 4.2 years (mean, 11.7 years; range, 4.2-20.3 years), and in the normal anatomy group 4.7 years (mean, 16.1 years; range, 4.7-23.7 years) (Table 1 ).

Some demographic characteristics and surgical specifics were not equally divided between groups (Tables 1, 2). Three factors that were potentially confounding factors for outcome of aseptic component loosening were an increased $(\mathrm{p}<0.01)$ percentage of women, a lower $(\mathrm{p}=0.03)$ mean weight, and a lower $(\mathrm{p}<0.01)$ mean height.

We used an anterolateral (Watson-Jones) approach in all patients. An osteotomy of the greater trochanter, in the

Table 1. Patient demographics

\begin{tabular}{lll}
\hline Demographics & $\begin{array}{l}\text { Hypoplastic } \\
\text { group }\end{array}$ & $\begin{array}{l}\text { Normal anatomy } \\
\text { group }\end{array}$ \\
\hline Number of patients (hips) & $77(86)^{1}$ & $198(231)$ \\
Man : Woman & $4: 73^{2}$ & $81: 117$ \\
Median age, years (range) & $65(23-80)^{3}$ & $69(36-85)$ \\
Mean followup, years (range) & $11.7(4.2-20.3)^{4}$ & $16.1(4.7-23.7)$ \\
Median weight, kg (range) & $64(38-111)^{5}$ & $68(46-115)$ \\
Median height, cm (range) & $160(143-189)^{6}$ & $168(144-192)$ \\
Median body mass index & $25.2(16.9-41.1)^{7}$ & $24.5(18.4-37.2)$ \\
Preoperative diagnosis (\%) & \multicolumn{3}{l}{} \\
DDH & $71 / 86(83 \%)$ & $58 / 231(25 \%)$ \\
Primary OA & $5 / 86(6 \%)$ & $148 / 231(64 \%)$ \\
Posttraumatic OA & $5 / 86(6 \%)$ & $7 / 231(3 \%)$ \\
Osteonecrosis & $4 / 86(5 \%)$ & $2 / 231(1 \%)$ \\
Reumatoid arthritis & $1 / 86(1 \%)$ & $58 / 231(25 \%)$ \\
Other & $0 / 86(0 \%)$ & $8 / 231(3 \%)$ \\
Number of previous hip & $35 / 86(41 \%)^{9}$ & $53 / 231(23 \%)$ \\
$\quad$ surgeries (\%) & & \\
\hline
\end{tabular}

Statistical differences between the two groups:

1 Student's t-test, $\mathrm{p}<0.01$.

2 chi square, $\mathrm{p}<0.01$.

3 Student's t-test, $\mathrm{p}<0.01$.

4 Student's t-test, $\mathrm{p}<0.01$.

5 Mann-Whitney U, p $<0.03$.

6 Student's t-test, $\mathrm{p}<0.01$.

7 chi square, $\mathrm{p}=0.58$.

8 chi square, $\mathrm{p}<0.01$.

9 chi square, $\mathrm{p}<0.01$. oblique sagittal plane, was performed in 22 hips $(26 \%)$ in the hypoplasia group and in 30 hips (13\%) in the normal anatomy group (Table 2). Fixation was accomplished with two lag screws perpendicular to the osteotomy plane and/or cerclage wiring from around the trochanteric tip, in a figure-eight shape around the proximal femur. The psoas tendon was released in all patients. The stem of the off-theshelf Weber Rotation Modular prosthesis (Allopro, Baar, Switzerland) we used is made of wrought CoNiCrMo alloy (Protasul ${ }^{\circledR}$ 10; Sulzer AG, Winterthur, Switzerland) and has a cylindrical neck (the trunnion), which is made of a cast CoCrMo alloy (Protasul ${ }^{\circledR}$ 2) composite welded to the stem (Fig. 2). The cross section of the stem is trapezoidal with rounded corners. It is available in a curved shape in four different sizes and in a straight shape in one size. At surgery, all patients of the hypoplastic group had an intramedullary canal, which was either too small for the standard 103-sized rasp (length, $10.9 \mathrm{~cm}$ from medial collar to the tip; width at the middle level, $11 \mathrm{~mm}$ ) to be used, or the shape of the proximal femur forced the 103 rasp into increased antetorsion and varus. We defined all such femurs as hypoplastic and used the smallest available 102 rasp (length, $9.6 \mathrm{~cm}$ from medial collar to the tip; width at the middle level, $9.5 \mathrm{~mm}$ ) to prepare the canal for a 102 stem. Because of the typical narrow width of the femoral canal in these hypoplastic femurs, it was necessary to enlarge the canal with a special drill before rasping. This

Table 2. Specifics of surgery and results

\begin{tabular}{|c|c|c|}
\hline Data for surgery & $\begin{array}{l}\text { Hypoplastic } \\
\text { group }\end{array}$ & $\begin{array}{l}\text { Normal anatomy } \\
\text { group }\end{array}$ \\
\hline $\begin{array}{l}\text { Number of trochanteric } \\
\text { osteotomies }\end{array}$ & $22 / 86(26 \%)^{1}$ & $30 / 231(13 \%)$ \\
\hline $\begin{array}{l}\text { Number of acetabular } \\
\text { roofplasties }\end{array}$ & $22 / 86(26 \%)^{2}$ & $64 / 231(28 \%)$ \\
\hline Spherical cup : flat cup & $69: 15$ & NR \\
\hline Ceramic : metal heads & $42: 42^{3}$ & $143: 83$ \\
\hline Mean HHS (range) & $88(51-100)^{4}$ & $89(53-100)$ \\
\hline $\begin{array}{l}\text { Number of surgery-related } \\
\text { complications (\%) }\end{array}$ & $4 / 86(5 \%)^{5}$ & $12 / 231(5 \%)$ \\
\hline $\begin{array}{l}\text { Number of aseptic } \\
\text { loosening stems (\%) }\end{array}$ & $6 / 86(7 \%)^{6}$ & $16 / 231(7 \%)$ \\
\hline $\begin{array}{l}\text { Number of aseptic } \\
\text { loosening cups (\%) }\end{array}$ & $4 / 86(5 \%)^{7}$ & $15 / 231(6 \%)$ \\
\hline 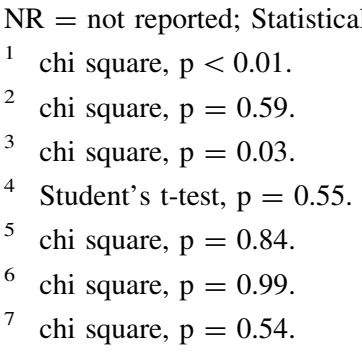 & differences bety & groups: \\
\hline
\end{tabular}




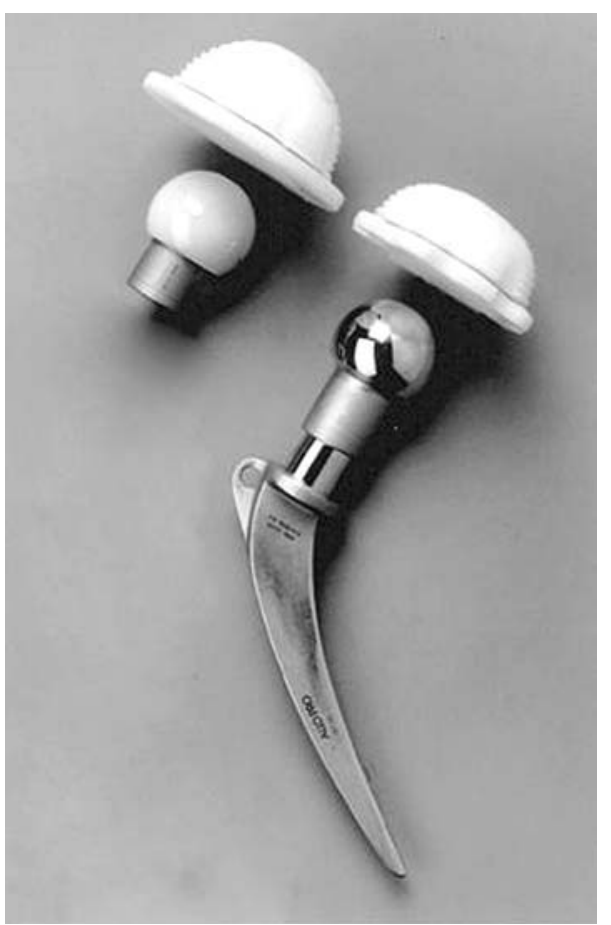

Fig. 2 In this picture, the hemispheric (left) and flat (right) socket with the curved stem of the 102 size Weber rotation total hip prosthesis with Protasul (right) and ceramic (left) heads with a trunnion bearing are shown.

drill has sharp edges on the side that cut out the endosteal inner side of the shaft, and a blunt tip that prevents perforation of the cortex. Generally, the cortex was thickened proximally. In the normal anatomy group the larger-sized stems (length, $10.9 \mathrm{~cm}$ to $15.2 \mathrm{~cm}$ from medial collar to the tip; width at the middle level 11 to $16 \mathrm{~mm}$ ) were used.

The all-polyethylene (RCH 1000; Chirulen ${ }^{\circledR}$, Hoechst, Germany) sockets had either a hemispheric or a flat outer contour. The latter was designed for a shallow dysplastic acetabulum. In the hypoplastic group the spherical cups had a diameter of $44 \mathrm{~mm}$ in 14 cases, $47 \mathrm{~mm}$ in $42,52 \mathrm{~mm}$ in $10,54 \mathrm{~mm}$ in one, and $57 \mathrm{~mm}$ in two. The flat cups had a diameter of $47 \mathrm{~mm}$ in 12 cases and $52 \mathrm{~mm}$ in three. In two hips of patients lost to followup, the sizes and shapes of the cups could not be traced. Twenty-two hips (26\%) in the hypoplastic group and 64 hips $(13 \%)$ in the normal anatomy group had deficient support of the socket as suggested by templating on preoperative radiographs, a Sharp angle greater than $42^{\circ}$, and/or less then $90 \%$ coverage of the cup observed during surgery. We performed superolateral roofplasty in these 22 hips. We use three triflange corticocancellous bone grafts taken from the resected femoral head and fixed these to the roughened supraacetabular iliac bone with 4.5-cortical lag screws. The interfaces between the iliac bone and the grafts are impacted with cancellous bone [12, 43].
Thirty-two-millimeter metal (Protasul ${ }^{\mathbb{R}} 2$ ) and ceramic (Biolox; Feldmühle, Plochingen, Germany) heads (Table 2) were used. The head was placed on a Protasul ${ }^{\circledR} 2$ cylinder. The cylinder was placed on the trunnion of the stem, providing a secondary joint with the possibility for rotation and slight axial translation. Three different lengths of cylinders were available, ranging from 2.5 to $3.5 \mathrm{~cm}$ (Fig. 2). We used low-viscosity Sulfix ${ }^{\circledR}$ (Sulzer AG) cement with a second-generation cementing technique, ie, intramedullary restriction of cement and vacuum suction in all patients. The stem was aimed in slight valgus in all patients (Fig. 3).

We (FHRdM, HMVdV, PPB, RKM) clinically examined patients at 6 weeks, 3 months, and 6 months postoperatively and annually thereafter. Patients completed a questionnaire to calculate the Harris hip score [27]. In two patients (three hips), a reliable hip score could not be obtained as a result of severe dementia and recent brain infarction, respectively. Thus, clinical evaluation was possible in 37 patients (43 hips).

Standard anteroposterior and lateral radiographs of the pelvis of the surgically treated hip were obtained at each visit. We (FHRdM, HMVdV, PPB, RKM) analyzed radiographs for signs of osteolysis or loosening according to Harris et al. [28] for the femoral component and Hodgkinson et al. [31] and DeLee and Charnley [15] for the acetabular implant.

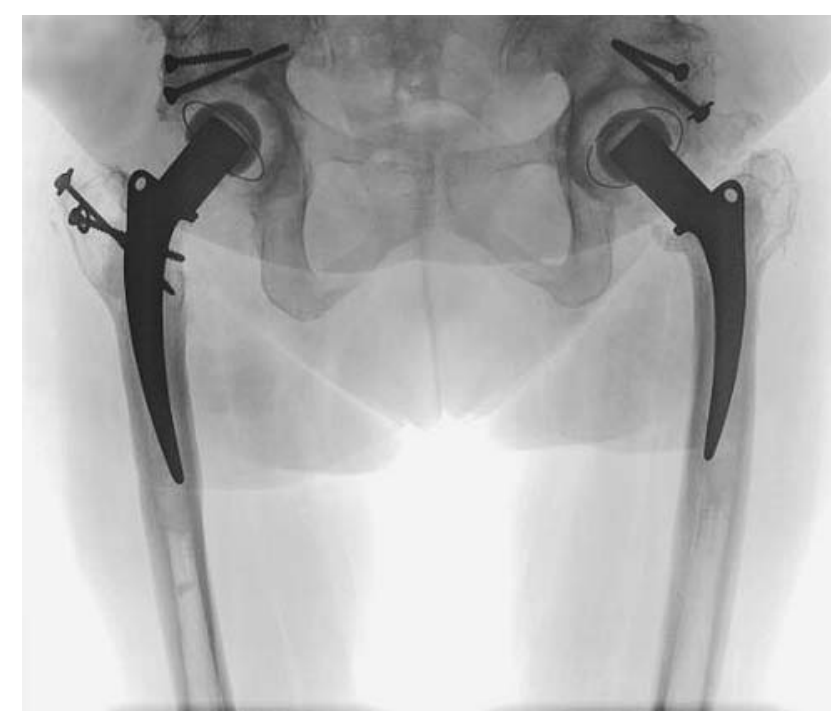

Fig. 3 The postoperative radiograph shows a 102-sized Weber stem on the left and a larger 103 stem on the right after a trochanteric osteotomy with bilateral 52-mm cemented cups and roofplasties 17 and 18 years, respectively, after the index operation. No demarcation around the components is seen. The acetabular roofplasties are completely integrated and the trochanteric osteotomy is healed. Periacetabular ossifications (Grade II according to Brooker) were asymptomatic. The Harris hip score at the time of the last followup was 87 points for the left side and 100 points for the right side. 
Survivorship for the femoral and acetabular components was analyzed using the life-table method [17], with three end points: (1) revision for any reason, (2) revision for aseptic loosening, (3) radiologic loosening (definite loosening of the stem and Grade III or IV loosening of the cup). We compared survivorship for all end points (log rank test) between the groups. We also compared the Harris hip scores (Student's t-test) and surgery-related complication rates and rates of aseptic loosening of the cup and stem (chi square). Statistical differences in demographic and surgical characteristics between groups were detected (Student's ttest and chi square for normal distribution and MannWhitney U test for nonuniform distribution). Characteristics that were different and potentially could lead to a confounding positive result of aseptic component loosening in the hypoplastic group were tested (Cox regression analysis).

\section{Results}

Survival rates for all end points were similar $(0.26<\mathrm{p}<0.81)$ in the two groups (Table 3). In the hypoplastic group 15-year survival of the small stem with aseptic loosening as an end point was $90 \%$ with a $95 \%$ confidence interval (CI) of $82 \%$ to $99 \%$; with revision for any reason as an end point survival was $90 \%$ with a $95 \%$ CI of $82 \%$ to $99 \%$; and with definitive radiographic loosening survival was $89 \%$ with a $95 \%$ CI of $79 \%$ to $99 \%$. Survival of the cup in the hypoplastic group with revision for aseptic loosening or revision for any reason as an end point was $91 \%$ with a $95 \%$ CI of $83 \%$ to $100 \%$, and with Grade III or IV radiographic loosening as the end point, survival was $91 \%$ with a $95 \%$ CI of $82 \%$ to $100 \%$. After correcting for differences in percentage of women, lower mean weight, and lower mean height, we observed no difference in survival based on aseptic stem and cup loosening $(\mathrm{p}=0.22$ and $\mathrm{p}=0.07$, respectively).

The revision rate for aseptic loosening of the stem was $7 \%$ in both groups. The revision rate for aseptic loosening of the cup also was similar in the two groups (5\% in the hypoplastic group and 6\% in the normal group) (Table 2). In the hypoplastic group two stems were revised for aseptic loosening. In two patients, both components were revised for aseptic loosening. One patient sustained a periprosthetic fracture and underwent revision of the stem and internal fixation. Three years later, the cup also was revised because of aseptic loosening. One hip had revision of the cup because of aseptic loosening and revision of the stem because of malrotation with subluxation of the joint. One 44-mm spherical cup was revised because of excessive wear (Table 4). At revision all of the trunnions functioned well and no macroscopic damage to the rotating bearing
Table 3. Survival analysis according to the life-table method with different end points

\begin{tabular}{lll}
\hline End point & $\begin{array}{l}\text { Hypoplastic group } \\
\text { (86 hips) } \\
\text { Survival rate } \\
\text { at 15-years (95\% CI) }\end{array}$ & $\begin{array}{l}\text { Normal anatomy } \\
\text { group (231 hips) } \\
\text { Survival rate at } \\
15 \text {-years (95\% CI) }\end{array}$ \\
\hline $\begin{array}{l}\text { Revision for any reason } \\
\text { Stem }\end{array}$ & \\
Cup & $90 \%(\mathrm{CI}, 82-99)^{1}$ & $89 \%(\mathrm{CI}, 84-94)$ \\
Revision for aseptic loosening & $92 \%(\mathrm{CI}, 87-96)$ \\
Stem & $90 \%(\mathrm{CI}, 82-99)^{3}$ & $93 \%(\mathrm{CI}, 89-97)$ \\
Cup & $91 \%(\mathrm{CI}, 83-100)^{4}$ & $94 \%(\mathrm{CI}, 90-98)$ \\
Radiologic loosening & \\
Stem & $89 \%(\mathrm{CI}, 79-99)^{5}$ & $86 \%(\mathrm{CI}, 80-92)$ \\
Cup & $91 \%(\mathrm{CI}, 82-100)^{6}$ & $89 \%(\mathrm{CI}, 83-95)$ \\
\hline
\end{tabular}

$\mathrm{CI}=$ confidence interval; Hypoplastic vs. normal anatomy group (log rank test):

$1 \mathrm{p}=0.79$.

${ }^{2} \mathrm{p}=0.50$.

${ }^{3} \mathrm{P}=0.26$.

${ }^{4} \mathrm{p}=0.40$.

${ }^{5} \mathrm{p}=0.67$.

${ }^{6} \mathrm{p}=0.77$.

Cox regression analysis: outcome revision aseptic stem corrected for length and gender showed no significant difference, $p=0.22$; outcome revision aseptic cup corrected for length and gender showed no significant difference, $\mathrm{p}=0.07$.

Table 4. Time between index operation and revision of components and reason for revision

\begin{tabular}{lcc}
\hline $\begin{array}{l}\text { Acetabular } \\
\text { component (years) }\end{array}$ & $\begin{array}{l}\text { Femoral } \\
\text { component (years) }\end{array}$ & Acetabular/Femoral \\
\hline- & 6.2 & $\begin{array}{c}\text { Aseptic loosening } \\
-\end{array}$ \\
5.7 & 17 & $\begin{array}{c}\text { Aseptic loosening } \\
\text { Aseptic loosening }\end{array}$ \\
12.9 & 5.7 & Aseptic loosening \\
10.5 & 12.9 & $\begin{array}{c}\text { Aseptic loosening/ } \\
\text { shaft fracture }\end{array}$ \\
7.8 & 7.5 & $\begin{array}{c}\text { Aseptic loosening/ } \\
\text { malpositioning }\end{array}$ \\
15.3 & 7.8 & Wear \\
\hline
\end{tabular}

was seen. There was no difference $(\mathrm{p}=0.35)$ in incidence of aseptic loosening between the flat and the spherical cups.

The mean Harris hip score was similar $(\mathrm{p}=0.55)$ in the two groups (mean, 88 and range, 51-100 in the hypoplastic group versus mean, 89 and range, 53-100 in the normal group). Average hip flexion was $104^{\circ}$ (range, $70^{\circ}-130^{\circ}$ ). A 1-cm leg-length discrepancy was present in five patients and a 4-cm discrepancy was present in one patient. 
Surgery-related complications occurred in 5\% of patients in both patient groups (Table 2). In the hypoplastic group one patient had a perforation of the femur treated by observation, one had a femoral fracture treated by cerclage wiring, one had a fracture of the greater trochanter after a previous intertrochanteric osteotomy treated with screw fixation, and one had surgical drainage of a hematoma. One patient had a deep calf venous thrombosis. All complications resolved completely after treatment. Late complications included a chronic infection in one patient who had few complaints and a hip score of 88 . Therefore, the prosthesis was not revised. After an osteotomy of the greater trochanter, one patient had a nonunion that healed after screw fixation, tension band wiring, and cancellous autologous bone grafting. This patient had a hip score of 87, no Trendelenburg sign, and some residual pain not necessitating revision surgery.

Radiographic analysis revealed one stem was definitively loose and one stem probably was loose, but because both patients had few complaints and with hip scores of 88 and 84, respectively, the stems were not revised. Eight cups had Grade I loosening, but hip scores ranged from 89 to 100 and none was revised. All acetabular roofplasties showed remodeling and incorporation into pelvic bone with reformation of trabeculae.

\section{Discussion}

Total hip arthroplasty in patients with hypoplasia of the femur is technically difficult because of the associated anatomic abnormalities. Several studies report a higher incidence of complications $[11,22,40,58]$ and less successful long-term results $[24,58]$ regarding stem fixation in comparison to primary THA in osteoarthritic hips of patients without hypoplasia. We asked whether the results in patients with OA treated with the smallest-sized cemented stem because of femoral hypoplasia were different from results in patients treated with a larger stem in an average-sized femur.

A limitation of this study is the lack of data regarding exact size of the proximal femur. Nevertheless, this size can be related to the size of the 102 component used. Another limitation is we did not measure clinical hip scores preoperatively. Because the pain caused by an osteoarthritic hip is the main reason to perform a THR, and pain is a dominant determinant of the Harris hip score and because hip scores at followup were high we can assume patients had substantial pain relief. Another concern is $11 \%$ of patients were lost to followup at the time of this study, but such a percentage is common and we believe does not jeopardize the conclusions; a mean of 6 years followup in this subgroup was still available, and patients who were lost to followup do not necessarily have poor results [36].

Our results with the cemented, small, curved 102 stem suggest a high survival rate after long-term followup, and results are at least comparable to results of patients treated with a larger-sized stem from our cohort. These results seem valid as the possible confounding factors of an increased percentage of women who have a lower risk of needing revision than men [30], and lower height and weight in the study group were corrected for. Also, several unfavorable demographic and surgical factors were present in the study group: femoral anatomy was altered, median age was younger and subsequent activity level presumably higher [38, 51], preoperative diagnosis of $\mathrm{DDH}$, incidence of previous surgery, and use of trochanteric osteotomy and metal heads all were increased in comparison to the normal anatomy group. An explanation could be that an optimal cementing technique could be even more beneficial in the case of a small femur; the volume of cement is smaller and therefore the increase of cement pressure is greater leading to better results $[32,37]$. Large series with long followups of the cemented off-the-shelf Charnley stem (Thackray, Leeds, England) used in patients with femoral hypoplasia associated with DDH also show high survival rates (Table 5) [35, 39, 41]. Although in finite element [53] and clinical studies [30, 42], cemented curved designs have inferior results compared with cemented straight stems, the curved Weber stem seems to perform equally well. The explanation could be that not only the frontal, but also the cross-sectional shape matters in stem fixation; the ovalshaped cross section of the Weber stem leaves a thicker cement mantle, especially at the proximomedial femur, as compared with stems with a box-shaped cross section [50], which is beneficial in long-term fixation [2, 6, 19]. Oh et al. [47] reported an increased incidence of loosening when they used cement for the off-the-shelf anatomic medullary locking stem. This might be because stem stiffness does not match the stiffness of cement, which is illustrated in the fact that stem loosening was dramatically lower when this porous-coated stem was used without cement.

Reports specifically addressing patients with hypoplastic femurs [16, 34, 47, 58] have advocated off-the-shelf [47, 58] and custom-made stems [16, 34] (Table 5). Huo et al. [34] and Di Fazio et al. [16] used a custom-made varus-offset cemented straight femoral component in 19 small femora. The clinical score (Hospital for Special Surgery) was 35 of 40, no complications were recorded, and the revision rate after a mean followup of 13 years was $6 \%$ [16, 34]. Woolson and Harris used a miniature cemented off-the-shelf straight femoral component [58]. The revision rate for aseptic stem loosening after a mean followup of 5 years was $5.5 \%$, the mean Harris hip score was 80 , and surgery-related complications were relatively 
high at $19 \%$ [58]. In both studies, the exact stem size was not stated.

In a recent meta-analysis of studies comparing off-theshelf cemented with uncemented THAs, cemented fixation had superior survival [44]. However, when femoral anatomy is different, some advocate an uncemented custommade stem [4]. The concept is to completely fill the femur with a component, which would lead to less stress shielding of the proximomedial femur compared with a cemented implant [33, 55]. However, this is difficult to achieve because stress shielding will only decrease when stem fit is precise for the entire proximal femur $[7,20,54,56]$ and the necessary determination of femoral internal geometry is still inaccurate [7]. Moreover, as a result of the smaller diameter at the femoral neck compared with the intertrochanteric area, it theoretically is impossible to insert a component from one side only and have a perfect anatomic fit [56]. Furthermore, fabrication of a custom-made prosthesis is time-consuming and costly, regardless of cement use.

Surgery-related complications were limited to 5\%, which equaled the complication rate in the normal anatomy group, whereas these rates in patients with femoral hypoplasia have been reported as high as $19 \%$ [11] and even $30 \%$ in extremely small femurs as seen in patients with achondroplasia [9]. We emphasize the need for a trochanteric osteotomy to obtain clear surgical exposure in these difficult cases. The incidence of nonunion after trochanteric osteotomy has been reported as high as $15 \%$ [10], but only $1 \%$ in our series. There were no dislocations, which might be explained by the use of 32-mm heads and the telescopic capacity of the rotating trunnion bearing, experience of the surgeon [29], and the use of an anterolateral approach [57].

In this series of relatively young patients after complex hip reconstructions resulting from a hypoplastic femur and OA, our data suggest the small cemented off-the-shelf Weber curved stem has high survival rates, is easy to use, is associated with few complications, and has outstanding long-term followup. Our results are in concordance with those of others for femoral hypoplasia and cemented offthe-shelf stems [35, 39, 41]. We agree with Capello [7] that if a cemented stem is used in small femora, the cured polymethylmethacrylate becomes part of the construct, which as a whole can be considered a customized implant. We believe there is no need for costly custom-made implants in patients with femoral hypoplasia.

Acknowledgments We thank Renee van Stralen for help and advice with writing this article and Inger Sierevelt for help with statistical analyses.

Open Access This article is distributed under the terms of the Creative Commons Attribution Noncommercial License which permits any noncommercial use, distribution, and reproduction in any medium, provided the original author(s) and source are credited. 


\section{References}

1. Anderson MJ, Harris WH. Total hip arthroplasty with insertion of the acetabular component without cement in hips with total congenital dislocation or marked congenital dysplasia. $J$ Bone Joint Surg Am. 1999;81:347-354.

2. Ayers D, Mann K. The importance of proximal cement filling of the calcar region: a biomechanical justification. J Arthroplasty. 2003;18(7 suppl 1):103-109.

3. Bargar WL. A conversation with William L. Bargar MD: custom cementless total hip replacement. Orthop Rev. 1987;16:27-37.

4. Bargar WL. Shape the implant to the patient: a rationale for the use of custom-fit cementless total hip implants. Clin Orthop Relat Res. 1989;249:73-78.

5. Bobak P, Wroblewski BM, Siney PD, Fleming PA, Hall R. Charnley low-friction arthroplasty with an autograft of the femoral head for developmental dysplasia of the hip: the 10- to 15year results. J Bone Joint Surg Br. 2000;82:508-511.

6. Bocco F, Langan P, Charnley J. Changes in the calcar femoris in relation to cement technology in total hip replacement. Clin Orthop Relat Res. 1977;128:287-295.

7. Capello WN. Fit the patient to the prosthesis: an argument against the routine use of custom hip implants. Clin Orthop Relat Res. 1989;249:56-59.

8. Charnley J, Feagin JA. Low-friction arthroplasty in congenital subluxation of the hip. Clin Orthop Relat Res. 1973;91:98-113.

9. Chiavetta JB, Parvizi J, Shaughnessy WJ, Cabanela ME. Total hip arthroplasty in patients with dwarfism. J Bone Joint Surg Am. 2004;86:298-304.

10. Clarke RP Jr, Shea WD, Bierbaum BE. Trochanteric osteotomy: analysis of pattern of wire fixation failure and complications. Clin Orthop Relat Res. 1979;141:102-110.

11. Crowe JF, Mani VJ, Ranawat CS. Total hip replacement in congenital dislocation and dysplasia of the hip. J Bone Joint Surg Am. 1979;61:15-23.

12. de Jong PT, Haverkamp D, van der Vis HM, Marti RK. Total hip replacement with a superolateral bone graft for osteoarthritis secondary to dysplasia: along-term follow-up. J Bone Joint Surg Br. 2006;88:173-178.

13. de Jong PT, van der Vis HM, de Man FH, Marti RK. Weber rotation total hip replacement: a prospective 5- to 20-year followup study. Clin Orthop Relat Res. 2004;419:107-114.

14. Decking R, Brunner A, Günther KP, Puhl W. [Total hip arthroplasty in congenital dysplasia of the hip: follow-up of a smalldimensioned, cemented straight stem][in German]. Z Orthop Ihre Grenzgeb. 2006;144:380-385.

15. DeLee JG, Charnley J. Radiological demarcation of cemented sockets in total hip replacement. Clin Orthop Relat Res. 1976;121:20-32.

16. DiFazio F, Shon WY, Salvati EA, Wilson PD Jr. Long-term results of total hip arthroplasty with a cemented custom-designed swan-neck femoral component for congenital dislocation or severe dysplasia: a follow-up note. J Bone Joint Surg Am. 2002;84:204-207.

17. Dobbs HS. Survivorship of total hip replacements. J Bone Joint Surg Br. 1980;62:168-173.

18. Dunn HK, Hess WE. Total hip reconstruction in chronically dislocated hips. J Bone Joint Surg Am. 1976;58:838-845.

19. Ebramzadeh E, Sarmiento A, McKellop HA, Llinas A, Gogan W. The cement mantle in total hip arthroplasty: analysis of long-term radiographic results. J Bone Joint Surg Am. 1994;76: 77-87.

20. Engh CA, Bobyn JD, Glassman AH. Porous-coated hip replacement: the factors governing bone ingrowth, stress shielding, and clinical results. J Bone Joint Surg Br. 1987;69:45-55.
21. Fredin H, Sanzén L, Sigurdsson B, Unander-Scharin L. Total hip arthroplasty in high congenital dislocation: 21 hips with a minimum five-year follow-up. J Bone Joint Surg Br. 1991;73:430-433.

22. Fredin HO, Unander-Scharin LE. Total hip replacement in congenital dislocation of the hip. Acta Orthop Scand. 1980;51:799802.

23. Garvin KL, Bowen MK, Salvati EA, Ranawat CS. Long-term results of total hip arthroplasty in congenital dislocation and dysplasia of the hip: a follow-up note. J Bone Joint Surg Am. 1991;73:1348-1354.

24. Gerber SD, Harris WH. Femoral head autografting to augment acetabular deficiency in patients requiring total hip replacement: a minimum five-year and an average seven-year follow-up study. J Bone Joint Surg Am. 1986;68:1241-1248.

25. Gill TJ, Sledge JB, Müller ME. Total hip arthroplasty with use of an acetabular reinforcement ring in patients who have congenital dysplasia of the hip: results at five to fifteen years. J Bone Joint Surg Am. 1998;80:969-979.

26. Haddad FS, Masri BA, Garbuz DS, Duncan CP. Primary total replacement of the dysplastic hip. Instr Course Lect. 2000;49:2339.

27. Harris WH. Traumatic arthritis of the hip after dislocation and acetabular fractures: treatment by mold arthroplasty: an endresult study using a new method of result evaluation. J Bone Joint Surg Am. 1969;51:737-755.

28. Harris WH, McCarthy JC Jr, O’Neill DA. Femoral component loosening using contemporary techniques of femoral cement fixation. J Bone Joint Surg Am. 1982;64:1063-1067.

29. Hedlundh U, Ahnfelt L, Hybbinette CH, Weckstrom J, Fredin H. Surgical experience related to dislocations after total hip arthroplasty. J Bone Joint Surg Br. 1996;78:206-209.

30. Herberts $\mathrm{P}$, Malchau H. How outcome studies have changed total hip arthroplasty practices in Sweden. Clin Orthop Relat Res. 1997;344:44-60.

31. Hodgkinson JP, Shelley P, Wroblewski BM. The correlation between the roentgenographic appearance and operative findings at the bone-cement junction of the socket in Charnley low friction arthroplasties. Clin Orthop Relat Res. 1988;228:105-109.

32. Huiskes R. Failed innovation in total hip replacement: diagnosis and proposals for a cure. Acta Orthop Scand. 1993;64:699-716.

33. Huiskes R, Weinans H, van Rietbergen B. The relationship between stress shielding and bone resorption around total hip stems and the effects of flexible materials. Clin Orthop Relat Res. 1992;274:124-134.

34. Huo MH, Salvati EA, Lieberman JR, Burstein AH, Wilson PD Jr. Custom-designed femoral prostheses in total hip arthroplasty done with cement for severe dysplasia of the hip. J Bone Joint Surg Am. 1993;75:1497-1504.

35. Iida $\mathrm{H}$, Matsusue $\mathrm{Y}$, Kawanabe K, Okumura $\mathrm{H}$, Yamamuro $\mathrm{T}$, Nakamura T. Cemented total hip arthroplasty with acetabular bone graft for developmental dysplasia: long-term results and survivorship analysis. J Bone Joint Surg Br. 2000;82:176-184.

36. Joshi AB, Gill GS, Smith PL. Outcome in patients lost to followup. J Arthroplasty. 2003;18:149-153.

37. Joshi RP, Eftekhar NS, McMahon DJ, Nercessian OA. Osteolysis after Charnley primary low-friction arthroplasty: a comparison of two matched paired groups. J Bone Joint Surg Br. 1998;80:585590 .

38. Kilgus DJ, Dorey FJ, Finerman GA, Amstutz HC. Patient activity, sports participation, and impact loading on the durability of cemented total hip replacements. Clin Orthop Relat Res. 1991;269:25-31.

39. Klapach AS, Callaghan JJ, Miller KA, Goetz DD, Sullivan PM, Pedersen DR, Johnston RC. Total hip arthroplasty with cement and without acetabular bone graft for severe hip dysplasia: a 
concise follow-up, at a minimum of twenty years, of a previous report. J Bone Joint Surg Am. 2005;87:280-285.

40. Linde F, Jensen J, Pilgaard S. Charnley arthroplasty in osteoarthritis secondary to congenital dislocation or subluxation of the hip. Clin Orthop Relat Res. 1988;227:164-171.

41. MacKenzie JR, Kelley SS, Johnston RC. Total hip replacement for coxarthrosis secondary to congenital dysplasia and dislocation of the hip: long-term results. J Bone Joint Surg Am. 1996;78: 55-61.

42. Malchau H, Herberts $\mathrm{P}$, Ahnfelt L. Prognosis of total hip replacement in Sweden: follow-up of 92,675 operations performed 1978-1990. Acta Orthop Scand. 1993;64:497-506.

43. Marti RK, Schüller HM, van Steijn MJ. Superolateral bone grafting for acetabular deficiency in primary total hip replacement and revision. J Bone Joint Surg Br. 1994;76:728-734.

44. Morshed S, Bozic KJ, Ries MD, Malchau H, Colford JM Jr. Comparison of cemented and uncemented fixation in total hip replacement: a meta-analysis. Acta Orthop. 2007;78:315-326.

45. Mulroy RD Jr, Harris WH. Failure of acetabular autogenous grafts in total hip arthroplasty: increasing incidence: a follow-up note. J Bone Joint Surg Am. 1990;72:1536-1540.

46. Numair J, Joshi AB, Murphy JC, Porter ML, Hardinge K. Total hip arthroplasty for congenital dysplasia or dislocation of the hip: survivorship analysis and long-term results. J Bone Joint Surg Am. 1997;79:1352-1360.

47. Oh KJ, Imrie S, Hwang K, Ramachandran R, Shegog M, Goodman SB. Total hip arthroplasty using the miniature Anatomic Medullary Locking stem. Clin Orthop Relat Res. 2006;447:85-91.

48. Perka C, Fischer U, Taylor WR, Matziolis G. Developmental hip dysplasia treated with total hip arthroplasty with a straight stem and a threaded cup. J Bone Joint Surg Am. 2004;86:312-319.
49. Rodriguez JA, Huk OL, Pellicci PM, Wilson PD Jr. Autogenous bone grafts from the femoral head for the treatment of acetabular deficiency in primary total hip arthroplasty with cement: longterm results. J Bone Joint Surg Am. 1995;77:1227-1233.

50. Scheerlinck T, Casteleyn PP. The design features of cemented femoral hip implants. J Bone Joint Surg Br. 2006;88:1409-1418.

51. Schmalzried TP, Shepherd EF, Dorey FJ, Jackson WO, dela Rosa M, Fa'vae F, McKellop HA, McClung CD, Martell J, Moreland JR, Amstutz HC. The John Charnley Award: wear is a function of use, not time. Clin Orthop Relat Res. 2000;381:36-46.

52. Spangehl MJ, Berry DJ, Trousdale RT, Cabanela ME. Uncemented acetabular components with bulk femoral head autograft for acetabular reconstruction in developmental dysplasia of the hip: results at five to twelve years. J Bone Joint Surg Am. 2001;83:1484-1489.

53. Stolk J, Maher SA, Verdonschot N, Prendergast PJ, Huiskes R. Can finite element models detect clinically inferior cemented hip implants? Clin Orthop Relat Res. 2003;409:138-150.

54. Stulberg SD, Stulberg BN, Wixson RL. The rationale, design characteristics, and preliminary results of a primary custom total hip prosthesis. Clin Orthop Relat Res. 1989;249:79-96.

55. Van Rietbergen B, Huiskes R, Weinans H, Sumner DR, Turner TM, Galante JO. ESB Research Award 1992: the mechanism of bone remodeling and resorption around press-fitted THA stems. J Biomech. 1993;26:369-382.

56. Walker PS, Robertson DD. Design and fabrication of cementless hip stems. Clin Orthop Relat Res. 1988;235:25-34.

57. Woo RY, Morrey BF. Dislocations after total hip arthroplasty. J Bone Joint Surg Am. 1982;64:1295-1306.

58. Woolson ST, Harris WH. Complex total hip replacement for dysplastic or hypoplastic hips using miniature or microminiature components. J Bone Joint Surg Am. 1983;65:1099-1108. 